TP Periodica Polytechnica

Mechanical Engineering

61(1), pp. 23-29, 2017

DOI: 10.3311/PPme.9092

Creative Commons Attribution (i)

RESEARCH ARTICLE

\section{The Numerical Damage Modeling of the Mechanical Bolted Assemblies under Fretting Solicitation}

\author{
Nour El Houda Cheriet ${ }^{1}$, Mohammed Sehoul ${ }^{1}$, \\ Mohamed Benguediab ${ }^{2 *}$, Benattou Bouchouicha ${ }^{2}$
}

Received 16 February 2016; accepted after revision 02 September 2016

\begin{abstract}
The purpose of this work is to shed light on the problem of the fretting damage of a mechanical assembly bolted in three dimensions. This study requires the analysis of the stress fields in the Cartesian coordinates in terms of the angle and the radius of the contact areas. It also requires the determination of the initiation's position and the crack's propagation. In this study, we focus on numerical modeling using the ANSYS computer. The results obtained in the form of nodal solutions show in details the positions of the stress concentrations and the formation of the bolted assembly. The contact surface between the plates (or contact elements) is characterizing by a contact pressure, Adhesion and gap. The results obtained have allowed us to determine the stress that triggered the initiation and crack propagation as well as the position of the damaged area by the fretting.
\end{abstract}

\section{Keywords}

fretting, bolted assembly, contact modelling, damage area, finite element

\footnotetext{
${ }^{1}$ Laboratory of Materials and Reactive Systems LMSR, University Djillali, Liabes Sidi Bel Abbes, Algeria

${ }^{2}$ University Djillali, Liabes Sidi Bel Abbes, Algeria

*Corresponding author, e-mail: benguediabm@gmail.com
}

\section{Introduction}

The Fretting fatigue was observed in many industrial mechanical components such as bolted joints, blade disc attachment in turbine, wire ropes, and shrink-fitted shafts. Among these applications, bolted joints are mechanical fasteners that are widely used in engineering structural, such as vehicles and air-planes since they have longer fatigue lifetime than welded, riveted and pinned joints [1]. Furthermore, the location of each fastener hole is inherently a localized stress concentration and a potential source for fatigue crack initiation and propagation under cyclic loading [2]. Therefore, many studies have focused on the fatigue and fretting fatigue behavour of bolted joints. The group of Chakherlou applied both experiments and FEA to study the parameters affecting the fatigue lifetime of DBLJ, such as coefficient of friction, clamping force [3] and interference fit between the hole and bolt [4]. Recently, the same group estimated the fatigue life of DBLJ by six different multi-axial fatigue criteria and found that Crossland's criterion had the best accuracy for all specimens [5].

Since the early work on the fretting phenomenon directed by Eden et al. [6], substantial enhancements were realised on this phenomenon tests and standardization, experimental observations, damage mechanisms, modelling, industrial case studies, and on the use of coatings or lubrication to minimize interface the fretting phenomenon $[3,7,8]$.

The normal load of contact and relative displacement are key factors that control the fretting wear or fretting fatigue. The fretting also occurs at the contact interface of the joint part due to relative repeated motion $[9,10]$. To ensure good contact reliability and improve performance, it is necessary to study the distribution of forces on the contact area and the stress field produced by them $[11,12]$. This area is very sensitive to repeated stresses that lead to crack initiation due to the high stress concentration at the edge of the hole $[13,14]$.

In study conducted by Juoksukangas et al. [15], the effect of the contact edge geometry on fretting fatigue behavior of a complete contact was studied with quenched and tempered steel and using a 2D elasto-plastic finite element model of the contact configuration to calculate cracking risks for complete 
and almost complete contact geometries. Others research have shown the effect of contact forces numerically and experimentally. The effect of contact forces on the fretting fatigue behavior of bolted plates with $5086 \mathrm{H} 24 \mathrm{Al}$-alloy was investigated by Benhamena et al. [16]. Fretting fatigue experiments and numerical simulation with FEM have shown that the sites of crack initiation change from the edge of the central hole to close the border of contact and the fretting fatigue life increases in increasing of contact forces. In others study conducted by Benhamena et al. [17], a three-dimensional finite element model was developed to predict the mechanical behavior of bolted joints. The effect of clamping torque on fatigue behavior and failure mode was investigated in bolted assemblies. Numerical results were validate experimentally and shown that the magnitude of the clamping torque and the level of cyclic loading determine the mode failure of bolted assemblies. In recent investigation, Juoksukangas et al. [18] have studied numerically and experimentally the effect of different operating and design parameters of a single bolted joint on fretting fatigue life. Results shown that the fretting fatigue life decreased when increasing the bulk stress and also when increasing the preload.

In this paper, the position of the stress concentration, and stresses caused the initiation and propagation of cracks under fatigue fretting are investigated [19-21]. Additionally, the damaged fretting area [22] is detected through deformations and displacements fields using numerical modelling.

\section{Finite element modelling}

According to the dimensions of the structure, a three dimensional model was generated using the commercial software ANSYS (ANSYS 14) in order to determine and to perform the analyses of stress field at contact zone.

\subsection{Material}

The material used for modeling the component flat of double lap joint is Aluminum alloy 7075-T6. There proprieties are taking from Military Handbook 5H [23] (Table 1). The material for the bolt is high-strength and high grade alloy steel (AJAX Steel Bolt Class 8.8 and UNBRAKO Steel Bolt Class 12.8). Typical Young's modulus and Poisson's ration for this material are $210,000 \mathrm{MPa}$ and 0.3 respectively [23].

Table 1 Mechanical proprieties of Aluminium alloy 7075-T6

\begin{tabular}{ll}
\hline Young'sModulus E $(\mathrm{Mpa})$ & 71000 \\
\hline Poisson's Ratio $v$ & 0.33 \\
Yield Stress $\sigma_{\mathrm{E}}(\mathrm{Mpa})$ & 412 \\
Ultimate Stress $\sigma_{\mathrm{u}}(\mathrm{Mpa})$ & 590 \\
Strength coefficient K $(\mathrm{MPa})$ & 850 \\
hardening exposant & 0.035 \\
\hline
\end{tabular}

The behaviour of the materials (Aluminum alloy: 7075-T6) used in this study were assumed to follow a Ramberg-Osgood law:

$$
\sigma=E \varepsilon_{e}+K \varepsilon_{p}^{n}
$$

\subsection{Geometry of the model}

The Figure 1 presents the geometry of the bolted assembly considered to this numerical analysis. [24]
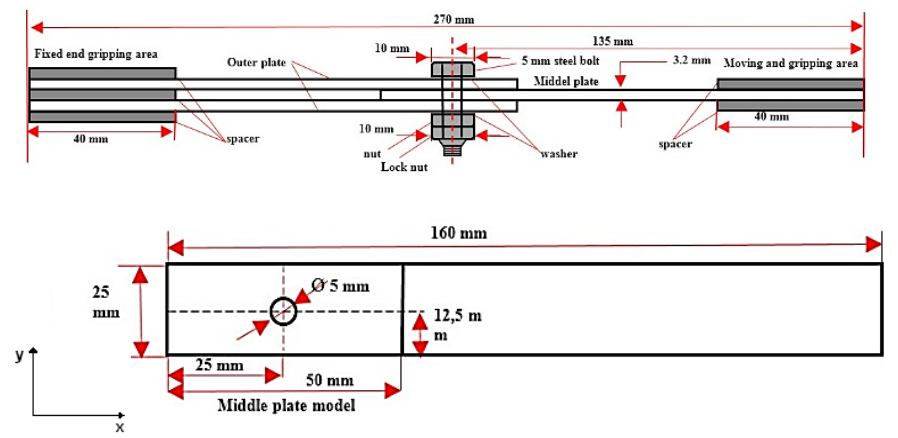

Fig. 1 The double lap joint Geometry of Aluminium alloy 7075-T6 [21]

In this modeling the fasteners (screw, nut counter-nut discs), are regarded as rigid bodies in the finite element model. Figure 2 shows the boundary conditions and the conditions of loading in statics.

A three-dimensional brick elements (SOLID45) is used for modeling of bolted assembly, this element is defined by eight nodes and each having three degrees of freedom. In addition, a surface-to-surface contact element, which consists of contact elements (CONTAC173) and target surface elements (TARGE169), is used on the interfaces between all connected parts of bolted assembly in order to simulate numerically the contact problems.

Friction between the contact surfaces at the connection is modeled using the classical Coulomb model, where the friction coefficient was set at 0.2 .
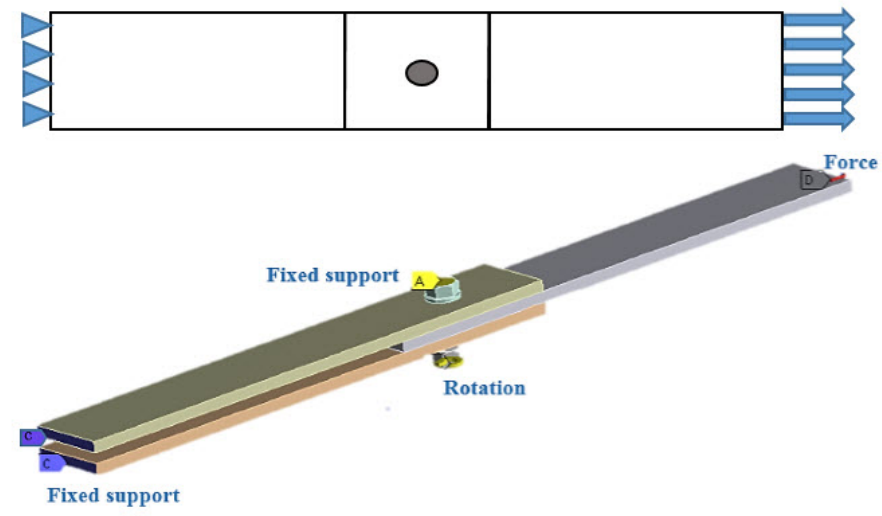

Fig. 2 Boundary conditions and loading condition 
The theory of incremental plasticity is introduced to modelling the material nonlinearity (elasto-plastic analysis). The iterative method of Newton-Raphson is used as an approach to solve nonlinear equations by finite elements.

The details of the finite elements model and the bolted assembly mesh are represented on Fig. 3 .

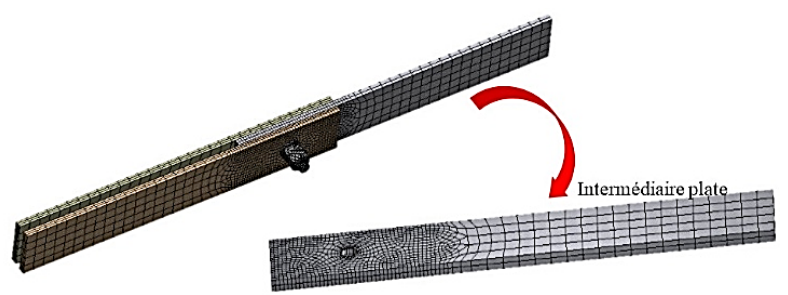

Fig. 3 Finite elements detail model: the bolted assembly Mesh

\subsection{Quantity of tightening torque}

The method used in this modeling to carry out the tightening torque is the method of the turn of nut. This method is based on a predetermined rotation of the nut [24]

The tightening can be achieved in two ways as follows:

- The bolt is first made "hand tight" and then turned further by a specified amount. The contact surfaces must fit snugly before the bolts are tightened.

- Using a percussion wrench, the bolt is first tightened until the plies of the joint achieve a snug fit (when the percussion wrench goes over to hammering), after which the nut is further turned by the amount:

$$
\theta=90^{\circ}+\sum t+d
$$

$\theta$ is rotation in degrees.

$t$ is the total thickness of plates assembled in "mm".

$d$ is the diameter of the bolt in "mm".

The purpose of this method is to rotate the nut sufficiently to take the bolt well into the plastic state (See Fig. 4). The shank tension is then comparatively insensitive to variation in the nut rotation, while a large reserve exists before rupture occurs.

It should be remembered that the ductility of the bolt largely depends on the length of the threaded portion. Care must be taken with short bolts which have only a small amount of thread in the grip ( 5 threads is a minimum).

A detailed analysis was carried out for each stress component between the hole and the contact area edges in the numerical model in order to analyze the combined effect of the tightening torque, and the cyclic load on the distribution of the stress field and to locate correctly the place of crack initiation in the contact area (Fig. 4).

\subsection{The stress filed analysis}

The polar coordinate is chosen for the simulation, in order to well define the various positions and orientations in the zone of contact, which are presented in Fig. 5 below.

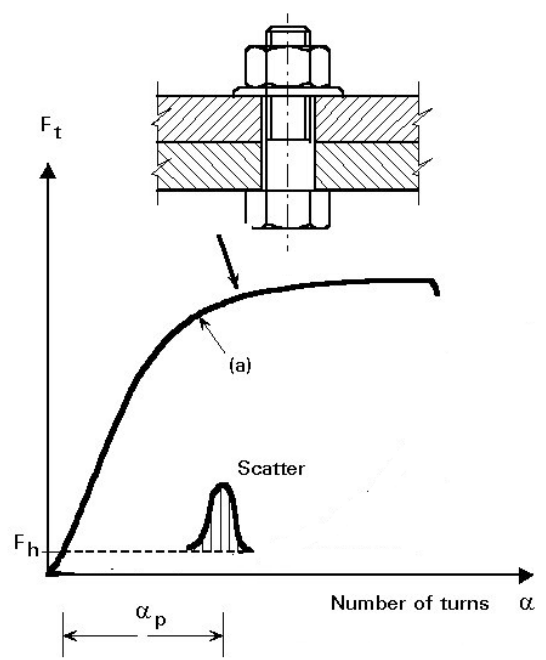

Plates are flat. After tightening $\left(\mathrm{F}_{\mathrm{h}}\right)$ the required preload is obtained $\left(\alpha_{\mathrm{P}} \square\right.$ prescribed number $\square$ of turns)

Fig. 4 Preloading with the turn of the nut method

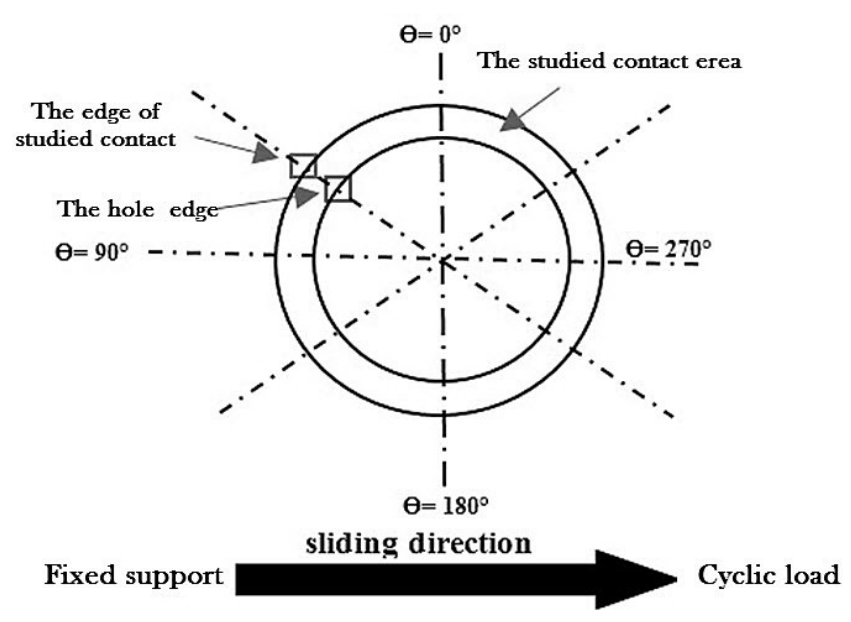

Fig. 5 Representation of the contact area (position and orientation).

$$
\left\{\begin{aligned}
2.5 \mathrm{~mm} & \leq r \leq 12.5 \\
r & =f(\theta)
\end{aligned} \text { and } 0 \leq \theta \leq 360^{\circ}\right.
$$

The Cartesian coordinate: $-25 \leq x \leq 25 \mathrm{~mm}$, and

$$
-12.5 \leq y \leq 12.5 \text {. }
$$

Figure 6 shows the Iso values of the Von Mises equivalent stress in the contact area only on the intermediate Aluminium plate under the same loading conditions

We notice that the value of this stress $\sigma_{\text {von Mises }}=269.31 \mathrm{MPa}$ is constant, and that the distribution is identical on all the surface of the contact area, therefore it is not localized in a defined position between the hole edge and the contact area edge. 


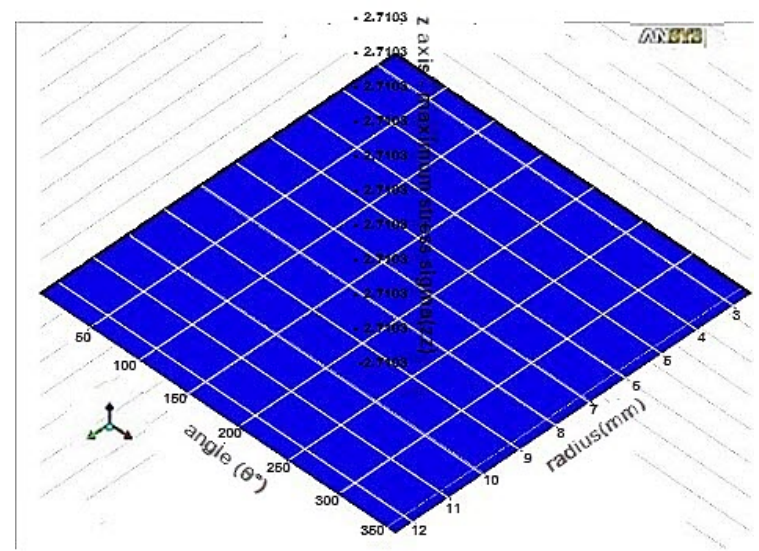

Fig. 6 Distribution of the Von-Mises equivalent stress in contact area edge

$$
\sigma_{\text {von Mises }}=\mathrm{f}(\mathrm{r}, \theta)
$$

\section{Results and discussion}

\subsection{Stress distribution in the contact area}

These results cannot precisely predict the position of the beginning. Consequently, the results can find the value of the stress to localize the place of the crack initiation in the contact area.A detailed analysis was carried out for each stress component between the hole and the contact area edges in the numerical model in order to analyze the combined effect of the tightening torque $\theta=106.6^{\circ}$, and the cyclic load $(\mathrm{F}=12 \mathrm{kN})$ on the distribution of the stress field and to locate correctly the place of crack initiation in the contact area. (See Fig. 7, 8, 9, 10, 11 and 12).

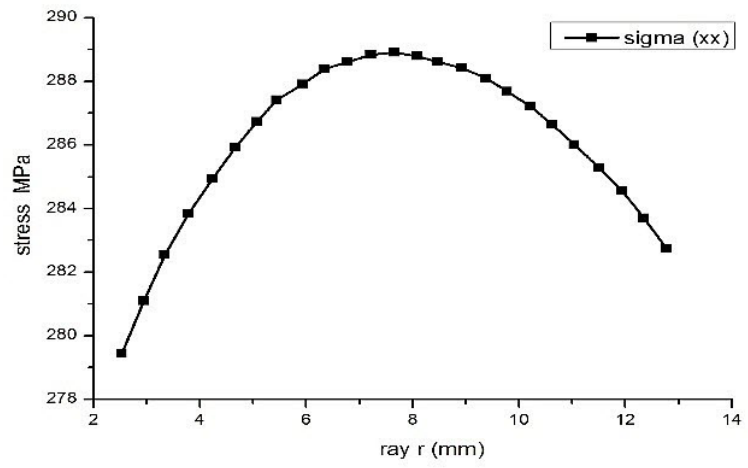

Fig. 7 Normal Stress Distribution in the contact area $\sigma_{x x}=f(r, \theta)$

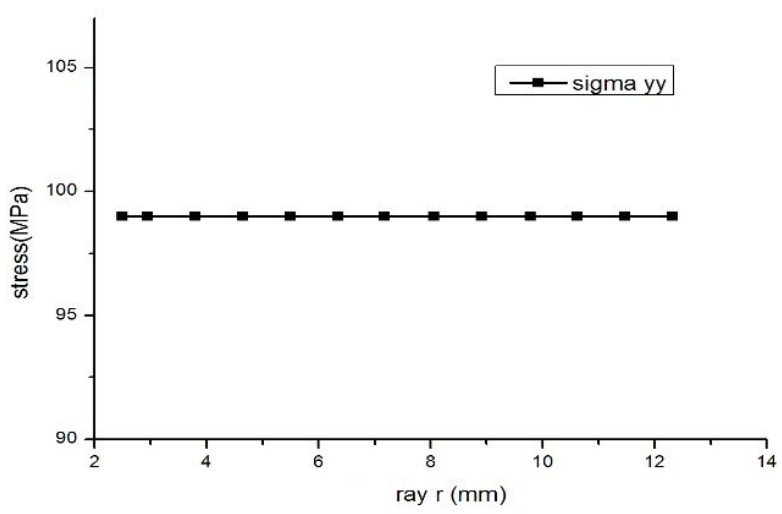

Fig. 8 Normal Stress Distribution in the contact area $\sigma_{y y}=f(r, \theta)$

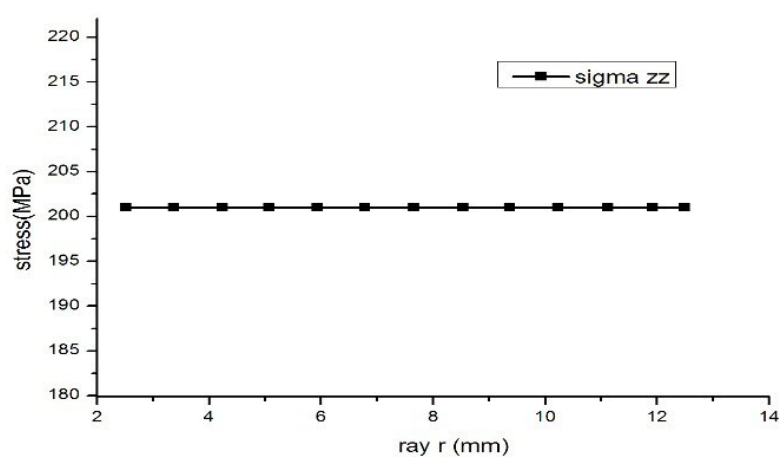

Fig. 9 Normal Stress Distribution in the contact area $\sigma_{z z}=f(r, \theta)$

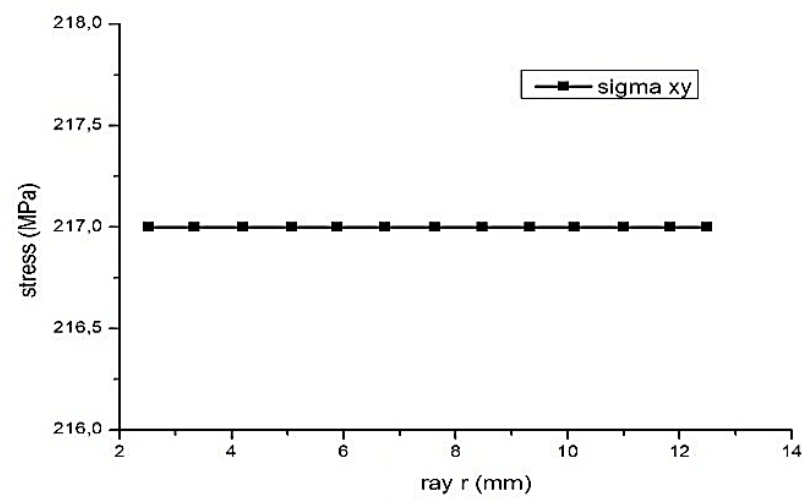

Fig. 10 Shear Stress Distribution in the contact area $\sigma_{x y}=f(r, \theta)$

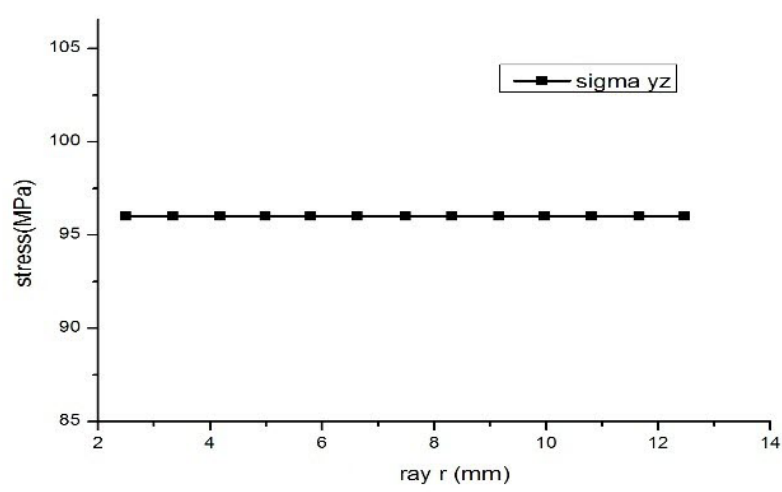

Fig. 11 Shear Stress Distribution in the contact area $\sigma_{y z}=f(r, \theta)$

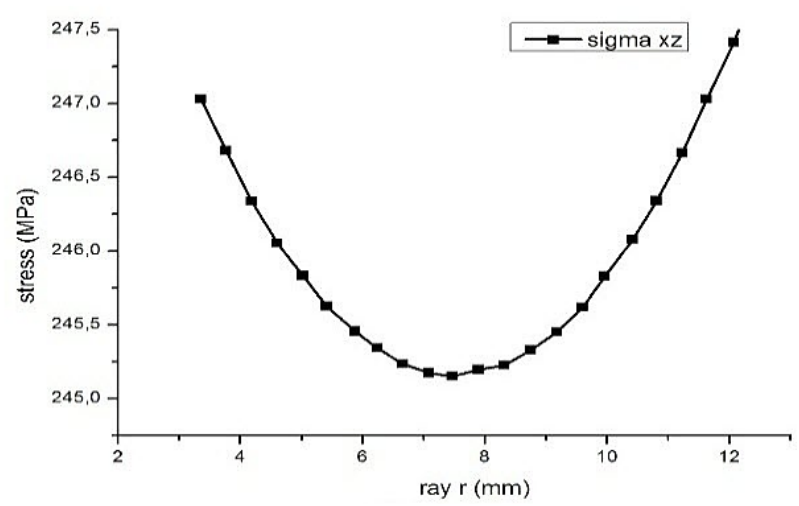

Fig. 12 Shear Stress Distribution in the contact area $\sigma_{x z}=f(r, \theta)$ 
From the Fig. 7, 8, 9, 10, 11 and 12, we see that the sign of all the components of stress according to the ray $\left(\sigma_{\mathrm{xx}} ; \sigma_{\mathrm{yy}} ; \sigma_{\mathrm{zz}}\right.$; $\left.\sigma_{\mathrm{xy}} ; \sigma_{\mathrm{yz}} ; \sigma_{\mathrm{xz}}\right)$ raised between the hole edge and the contact area edge is positive. The stresses $\left(\sigma_{\mathrm{yy}} ; \sigma_{\mathrm{zz}} ; \sigma_{\mathrm{xy}} ; \sigma_{\mathrm{yz}}\right)$ takes a constant values $\sigma_{\mathrm{yy}}=100 \mathrm{MPa} ; \sigma_{\mathrm{zz}}=219.23 \mathrm{MPa} ; \sigma_{\mathrm{xy}}=200 \mathrm{MPa}$ and $\sigma_{\mathrm{yz}}$ $=95 \mathrm{MPa}$ whatever is the ray value.

At the hole edge $r=2.5 \mathrm{~mm}$, the stress $\sigma_{x x}$ takes minimal value $\sigma_{\mathrm{xx}}=282 \mathrm{MPa}$ and increases up to a maximal value at $\sigma_{x x}=288.87 \mathrm{MPa}$ at $\mathrm{r}=7.5 \mathrm{~mm}$, then $\sigma_{\mathrm{xx}}$ decreases in a symmetrical way to its minimal value $=279.5 \mathrm{MPa}$ at the contact area $\mathrm{r}=12.5 \mathrm{~mm}$. In an opposite way $\sigma_{\mathrm{xz}}$ takes a maximal value $\sigma_{\mathrm{xz}}=247 \mathrm{MPa}$ at the hole edge $\mathrm{r}=2.5 \mathrm{~mm}$ and decrease to at $\mathrm{r}=7.5 \mathrm{~mm}$. Then it increase up to take a maximal value $\sigma_{\mathrm{xz}}=248 \mathrm{MPa}$ at the contact area edge $\mathrm{r}=12.5 \mathrm{~mm}$.

\subsection{Iso-value of Stress distribution in the contact area}

The first observation from the reading of these graphs (Figs. 13, 14, 15, 16 and 17) indicates that the sign of all the stresses according to the angle $\left(\sigma_{\mathrm{xx}} ; \sigma_{\mathrm{yy}} ; \sigma_{\mathrm{xy}} ; \sigma_{\mathrm{yz}} ; \sigma_{\mathrm{xz}}\right)$ found between the hole edge and the contact area edge is positive. Each stress $\left(\sigma_{\mathrm{yy}} ; \sigma_{\mathrm{zz}} ; \sigma_{\mathrm{xy}} ; \sigma_{\mathrm{yz}}\right)$ is constant whatever $0 \leq \theta \leq 360^{\circ}$ and the stresses $\left(\sigma_{\mathrm{xx}} ; \sigma_{\mathrm{xz}}\right)$ are varied in function of the angle.

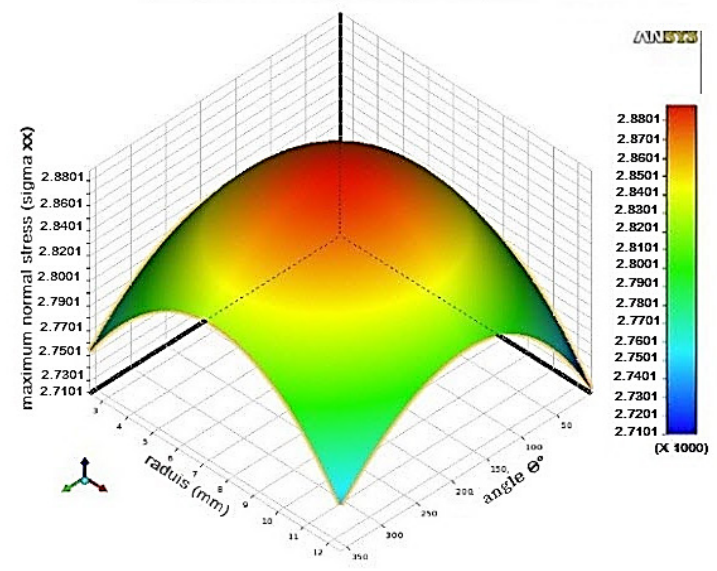

Fig. 13 Iso-values of normal stress distribution in contact area $\sigma_{x x}=f(r, \theta)$

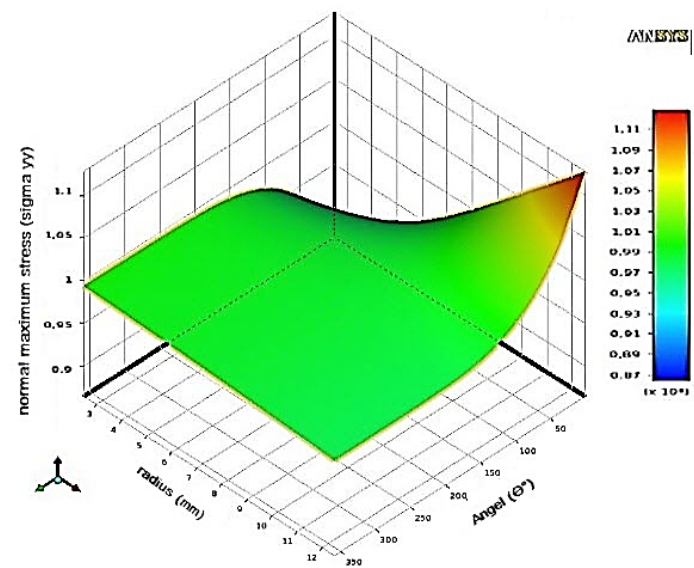

Fig. 14 Iso-values of normal stress distribution in contact area $\sigma_{y y}=f(r, \theta)$
In the position $\theta=178.81^{\circ} \cong 180^{\circ}$, the normal stress $\sigma_{x x}$ takes a maximum value $\sigma_{\mathrm{xx}}=288.87 \mathrm{MPa}$ then decreases continuously until it reaches its minimum value $\sigma_{x x}=279.43 \mathrm{MPa}$ to a position defined by $\theta=0^{\circ}$.
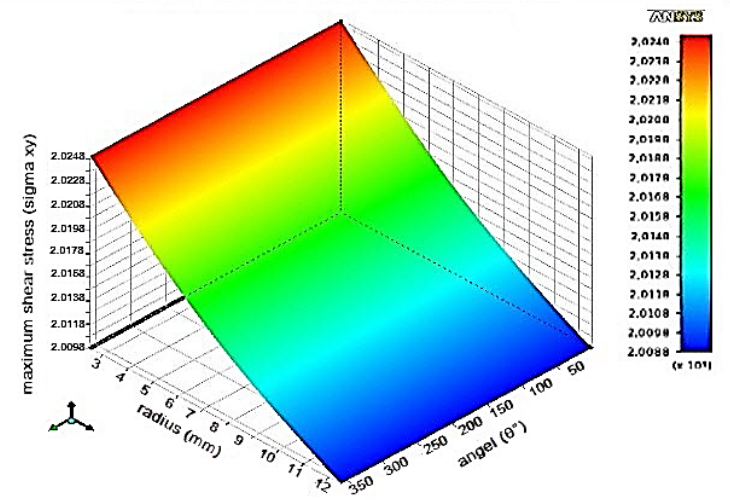

Fig. 15 Iso-values of shear stress distribution in contact area $\sigma_{x y}=f(r, \theta)$

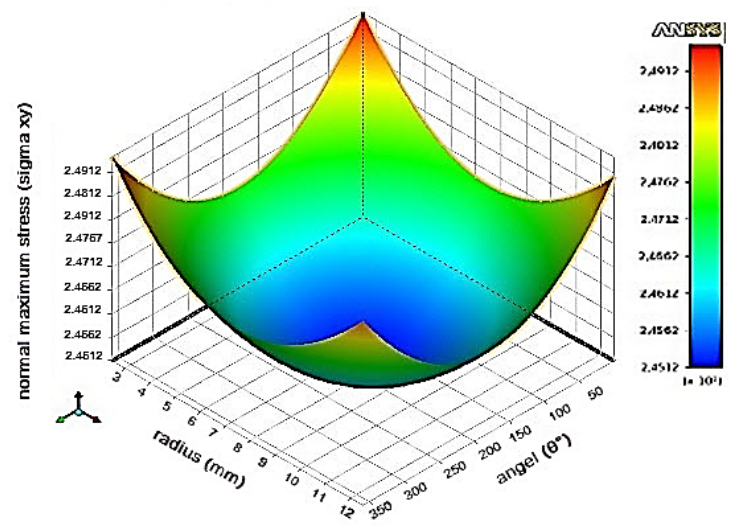

Fig. 16 Iso-values of shear Stress Distribution in the contact area $\sigma_{y z}=f(r, \theta)$

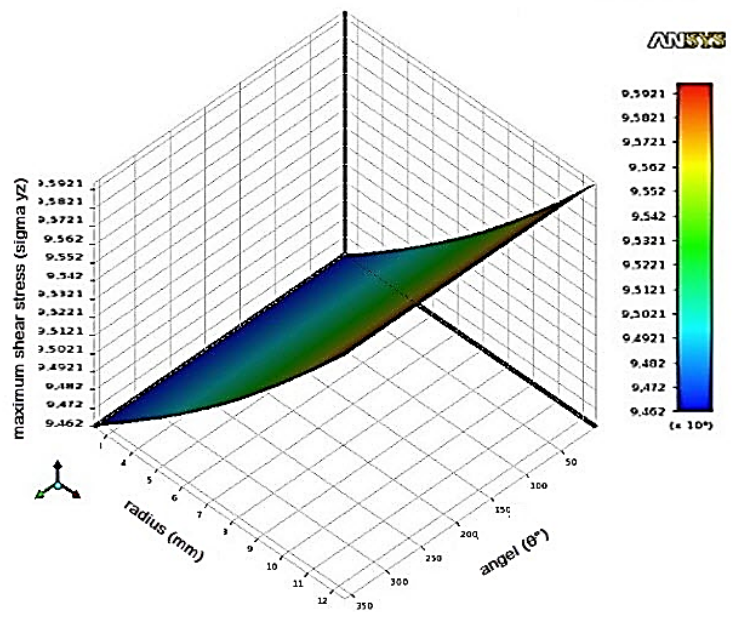

Fig. 17 Iso-values of shear Stress Distribution in the contact area $\sigma_{x z}=f(r, \theta)$

However, the shear stress $\sigma_{\mathrm{xz}}$ takes a minimum value $=$ $247 \mathrm{MPa}$ for $\theta=178.81^{\circ} \cong 180^{\circ}$ and increases continuously up to the maximum value $\sigma_{\mathrm{xz}}=248 \mathrm{MPa}$ for $\theta=0^{\circ}$. We can notice that the stress field according to the direction of the cyclic load takes a significant value. 
According to the direction of the tightening torque, stress takes a value $\sigma_{\mathrm{zz}}=219.23 \mathrm{MPa}$.

We can conclude that the mechanism of crack starting and propagation is controlled by the component of the constraint in relation to the direction of the cyclic load.

In view of the stress concentration phenomenon in mechanics, the node which corresponds to a defined position, by the angle $\theta=178.81^{\circ} \cong 180^{\circ}$ is more dangerous in the contact area because the stress component, which starts the crack initiation and the propagation of fretting fatigue in the flat, reaches its maximum value. This conclusion will be the first to be broken if a critical load is reached. In simulation, we notice that the stress concentration belongs to the contact area located at a ray $\mathrm{r} \leq 12.5 \mathrm{~mm}$. For more precision of the determination of the ray corresponding to this zone, it is necessary to analyse the distribution of the stresses between the hole edge and the contact area edge for a ray $\mathrm{r} \leq 12.5 \mathrm{~mm}$

Consequently, the node, which corresponds to a position defined by the angle $\mathrm{r}=7.5 \mathrm{~mm}$ is more dangerous in the contact area. This position corresponds to the preceding position $\theta=178.81^{\circ} \cong 180^{\circ}$ by the projection with the modelling geometry. We find that this position corresponds to a tilted plan of $\theta=90^{\circ}$ angle compared to the application plan of the cyclic load.

Finally, we found that the exactly position of crack initiation is $\left(\mathrm{r}=7.5 \mathrm{~mm} ; \theta=90^{\circ}\right)$, this results shows a good agreement between simulation and the experimentation according to the experimental work [24] (Fig. 18).

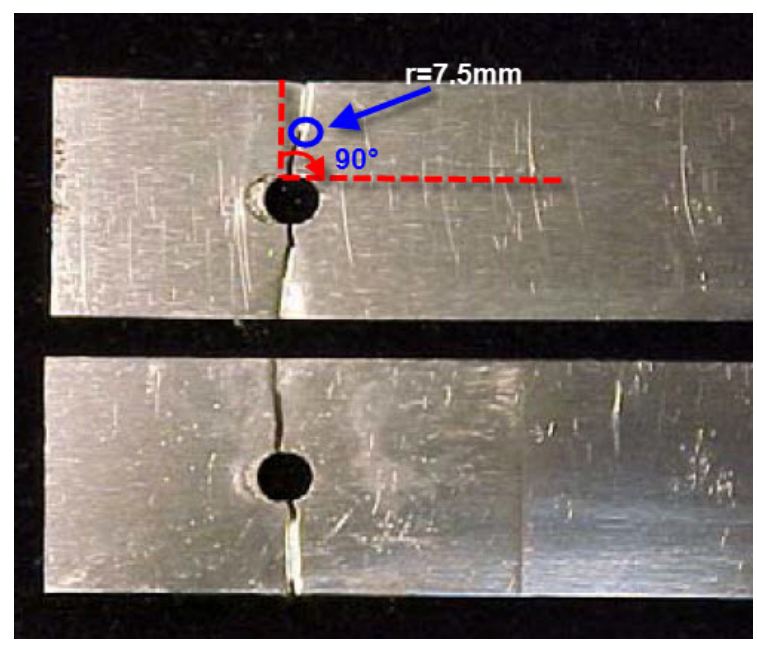

Fig. 18 Experimental results obtained by [24]

\section{Conclusion}

The numerical simulation carried out in $3 \mathrm{D}$, makes it possible to describe the real behaviour of a bolted assembly in fretting fatigue. The obtained results show that the tightening torque has an important role in load transfer.

The stress field distribution is affected by several parameters that can be summarized below:
- Technological parameters related to the design.

- Numerical parameters represented by the number of elements and the step of the computing time.

- The parts with strong stress concentrations of Von-Mises are generally found in the fasteners and the tracks of friction, causing mechanical phenomena (cracks, wear, rupture... etc).

- The torque intensity causes an increase of Von Mises stresses equivalent and increase of shear stresses, and an increase of normal stresses in the plates.

- The Von Mises stresses of the plates notably increase when aspect cyclic load and torque are coupled.

- The location of the crack initiation will be transferred to the edge the contact area in an inclined plane of an angle $\alpha=90^{\circ}$ from the sliding direction.

\section{References}

[1] Valtinat, G., Hadrych, I., Huhn, H. "Strengthening of riveted and bolted steel constructions under fatigue loading by preloaded fasteners-experimental and theoretical investigations." In: Proceedings of the international conference on connections in steel structures IV. AISC and ECCS, Roanoke, USA, Oct. 22-25, 2000. pp. 464-473.

[2] Chakherlou, T. N., Mirzajanzadeh, M., Vogwell, J. "Effect of hole lubrication on the fretting fatigue life of double shear lap joints: an experimental and numerical study." Engineering Failure Analysis. 16(7), pp. 2388-2399. 2009. https://doi.org/10.1016/j.engfailanal.2009.03.031

[3] Chakherlou, T. N., Razavi, M. J., Abazadeh, B. "Finite element investigations of bolt clamping force and friction coefficient effect on the fatigue behavior of aluminum alloy 2024-T3 in double shear lap joint." Engineering Failure Analysis. 29, pp. 62-74. 2013.

https://doi.org/10.1016/j.engfailanal.2012.11.004

[4] Chakherlou, T. N., Mirzajanzadeh, M., Abazadeh, B., Saeedi, K. "An investigation about interference fit effect on improving fatigue life of a holed single plate in joints." European Journal of Mechanics - A/solids. 29(4), pp. 675-682. 2010.

https://doi.org/10.1016/j.euromechsol.2009.12.009

[5] Esmaeili, F., Chakherlou, T. N., Zehsaz, M. "Prediction of fatigue life in aircraft double lap bolted joints using several multiaxial fatigue criteria." Materials Design. 59, pp. 430-438. 2014.

https://doi.org/10.1016/j.matdes.2014.03.019

[6] Eden, E. M., Rose, W. N., Cunningham, F. L "The endurance of metals." Proceedings of the Institution of Mechanical Engineers. 81(1), pp. 839974. 1911. https://doi.org/10.1243/PIME_PROC_1911_081_017_02

[7] Oskouei, R. H., Ibrahim, R. N. "Improving fretting fatigue behaviour of A1 7075-T6 bolted plates using electroless Ni-P coatings." International Journal of Fatigue. 44, pp. 157-167. 2012. https://doi.org/10.1016/j.ijfatigue.2012.05.003

[8] Fu, Y., Wei, J., Batchelor, A. W. "Some considerations on the mitigation of fretting damage by the application of surface-modification technologies." Journal of Materials Processing Technology. 99(1-3), pp. 231245. 2000. https://doi.org/10.1016/S0924-0136(99)00429-X

[9] Benhamena, A., Amrouche, A., Talha, N., Benseddiq, N. "Effect of contact forces on fretting fatigue behavior of bolted plates: Numerical and experimental analysis." Tribology. 48, pp. 237-245. 2012. https://doi.org/1016/j.triboint.2011.12.008 
[10] Szolwinski, M. P., Farris, T. N. "Observation, analysis and prediction of fretting fatigue in 2024-T351 aluminum alloy." Wear. 22(1), pp. 24-36. 1998. https://doi.org/10.1016/S0043-1648(98)00264-6

[11] Shinde, S. R., Hoeppner, D. W. "Fretting fatigue behaviour in 7075-T6 aluminum alloy." Wear. 261(3-4), pp. 426-434. 2006. https://doi.org/10.1016/j.wear.2005.12.015

[12] Yantio Njankeu Sabeya, G. R. "Comportement tribologique d'un alliage de titane traité et/ou revetu en fretting à débattement libre." (Tribological behaviour of a coated and treated titanium alloy under free displacements fretting condition.) PhD Thesis, L'Institut National Polytechnique de Toulouse. 2007. URL: http://ethesis.inp-toulouse.fr/archive/00000563/01/yantio.pdf (in French)

[13] Liu, J., Liu, D., Liu, Y. Y., Tang, C. B. "Finite Element Analysis for Fretting Contacting Stresses." Joumal of Mechanical Strength. 27(4), pp. 504-509. 2005.

[14] Terada, H. "Structural fatigue and joint degradation." International Journal of Fatigue. 23(S1), pp. 21-30. 2001. https://doi.org/10.1016/S0142-1123(01)00117-7

[15] Juoksukangas, J., Lehtovaara, A., Mäntylä, A. "The effect of contact edge geometry on fretting fatigue behavior in complete contacts." Wear. 308(1-2), pp. 206-212. 2013. https://doi.org/10.1016/j.wear.2013.06.013

[16] Benhamena, A., Amrouche, A., Talha, A., Benseddiq, N. "Effect of contact forces on fretting fatigue behavior of bolted plates: Numerical and experimental analysis." Tribology International. 48, pp. 237-245. 2012. https://doi.org/10.1016/j.triboint.2011.12.008

[17] Benhamena, A., Aminallah, L., Baltach, A., Aid, A., Benguediab, M., Amrouche, A., Benseddiq, N. "The fretting fatigue behavior of bolted assemblies." In: Design and Computation of Modern Engineering Materials, Advanced Structured Materials. (Öchsner, A., Altenbach, H. (eds.)), pp 187-204, Springer International Publishing, Switzerland. 2014.

https://doi.org/10.1007/978-3-319-07383-5_14
[18] Juoksukangas, J., Lehtovaara, L., Mäntylä, A. "Experimental and numerical investigation of fretting fatigue behavior in bolted joints." Tribology International. 103, pp. 440-448. 2016. https://doi.org/10.1016/j.triboint.2016.07.021

[19] Xu, J-Q., Mutoh, Y. "Stress field near the contact edge in fretting fatigue tests." JSME International Journal Series A Solid Mechanics and Material Engineering. 45(4), pp. 510-516. 2002. https://doi.org/10.1299/jsmea.45.510

[20] Mutoh, Y., Xu, J-Q. "Fracture Mechanics Approach to Fretting Fatigue and Problems to Be Solved." Tribology International. 36(2), pp. 99-107. 2003. https://doi.org/10.1016/S0301-679X(02)00136-6

[21] Hojjati-Talemi, R., Wahab, M. A., De Pauw, J., De Baets, P. "Prediction of fretting fatigue crack initiation and propagation lifetime for cylindrical contact configuration." Tribology International. 76, pp. 73-91. 2014. https://doi.org/10.1016/j.triboint.2014.02.017

[22] Maleki, H. R., Abazadeh, B. "Fretting Fatigue behavior of bolted single lap joints of aluminum alloys." World Academy of Science, Engineering \& Technology. 6(8), pp. 1509-1511. 2012.

[23] Military Handbook "Metallic Materials and Elements for Aerospace Vehicle Structures." MIL-HDBK-5H, 1 Dec 1998.

[24] Benhamena, A. "Contribution àl'etude Del'endommagement En Fretting Fatigue des assemblages par fixation: Cas Des Assemblages Rivetes." (Contribution to the Fretting Fatigue Damage Study of assemblies by fixation: Rivet Assemblies Case.) PhD Thesis, Sidi Bel Abbes, Algeria, 2010. (in French) 